\title{
Post-settlement mortality in Phragmatopoma virgini (Polychaeta: Sabellariidae) at the Mehuin Marine Reserve, Chile
}

\author{
Juan H. Zamorano, Carlos A. Moreno, William E. Duarte \\ Instituto de Ecología y Evolución, Facultad de Ciencias, Universidad Austral de Chile, Casilla 567, Valdivia, Chile
}

\begin{abstract}
We examined the likely cause of the dramatic decrease in abundance experienced by a population of reef-building polychaetes Phragmatopoma virgini Kinberg, 1867 at the low rocky intertidal of the Mehuin Marine Reserve, southern Chile. The abundance level there contrasts strongly with the levels of abundance that this species has outside the area. To determine if this decrease resulted from processes operating in the post-settlement stage, we offered textured and untextured cement plates as substrata for settling $P$. virgini. In addition, in order to assess the effect of mobile consumers on post-settlement mortality, we enclosed settlement plates in cages. After 18 mo of monitoring the abundance of recruits on the artificial plates, we determined that recruitment occurs throughout the year, but with a clear seasonal variation in intensity. Recruitment densities were highest on rough textured plates. The exclusion of consumers resulted in a major increase in the number of recruits on both types of surface. The higher density of recruits on the rough surfaces was probably the result of microenvironmental conditions that enhance settlement and survival of the new settlers by providing a refuge from mobile consumers, specifically dislodgement by rasping invertebrates. We concluded that the decrease observed in the population of $P$. virgini at the Marine Reserve is the result of higher postsettlement mortality produced by predation activity of high densities of mobile consumers within this reserve.
\end{abstract}

KEY WORDS: Polychaeta - Settlement - Phragmatopoma - Rocky intertidal - Marine reserve

\section{INTRODUCTION}

The persistence of the majority of sessile solitary animal populations that inhabit rocky substrata and have planktonic stages depends on the settlement of these larvae and on their subsequent survival to be counted as recruits. In most populations, both events undergo important fluctuations in space and time (Connell 1961, 1985a, b. Hawkins \& Hartnoll 1982, Keough 1983. Caffey 1985, Gotelli 1987). These fluctuations are generally associated with different sources of mortality operating during pre-and post-settlement stages (Denley \& Underwood 1979, Connell 1985b, Yund et al. 1987, Barry 1989, Stoner 1990).

Work on a range of different benthic organisms has revealed that one of the most common causes of postsettlement mortality is the action of mobile consumers. They affect newly settled juveniles directly by consum- ing them (Connell 1961, Keough \& Downes 1982 , Gaines \& Roughgarden 1985) and indirectly through grazing (Young \& Chia 1984, Davis 1988, Stoner 1990) or dislodgement (Denley \& Underwood 1979, Stoner 1990).

In systems subjected to a high perturbation frequency by mobile consumers, post-settlement mortality may assume considerable importance to the overall population dynamics of a species. A system that presents this characteristic is the community of the rocky intertidal of the Marine Reserve of Mehuin (southern Chile) where, as a result of exclusion of humans, several populations of mobile herbivores and carnivores have notably increased their densities. One of the immediate consequences of this phenomenon has been a decrease in the levels of abundance of their prey species in contrast to levels in areas outside the Reserve (Jara \& Moreno 1984, Moreno et al. 1984, 1986). 


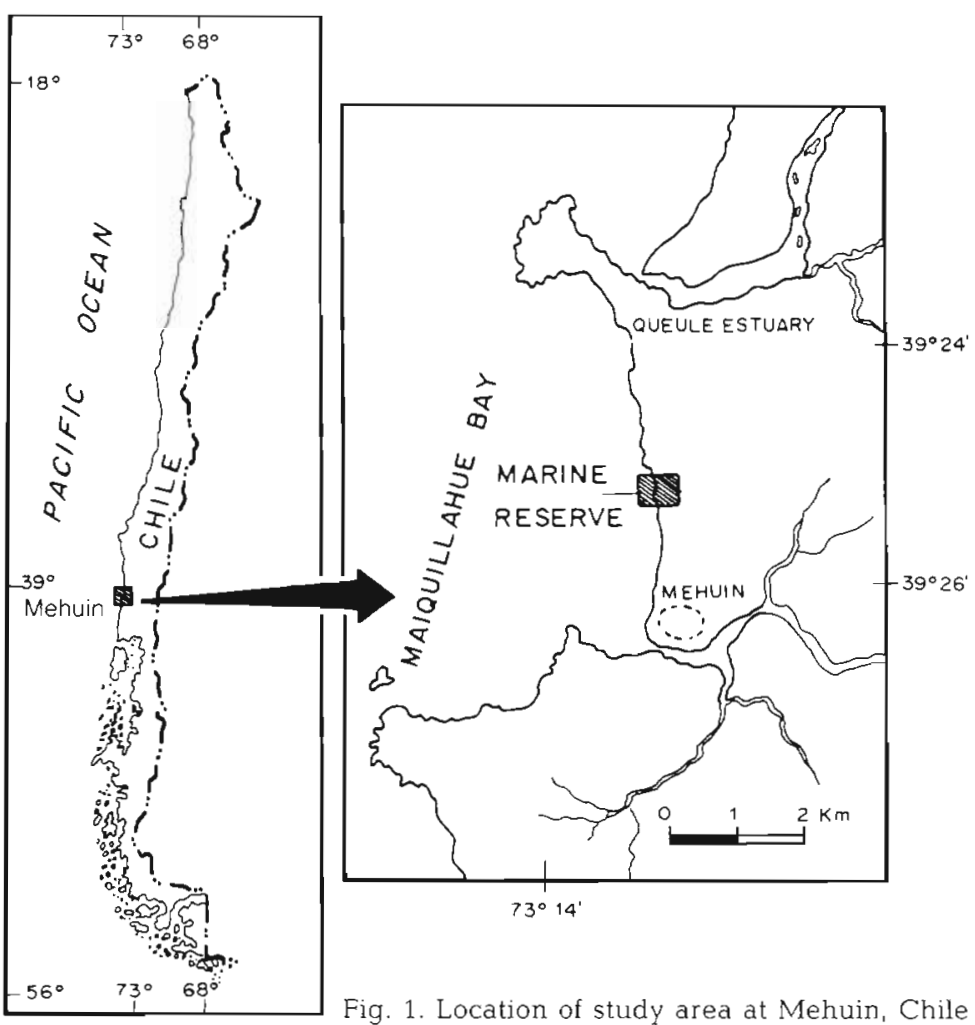

Chile has maintained as a Marine Reserve since 1978. The general topographic and climatic characteristics of the area are described in Jara (1980) and Jara \& Moreno (1984).

Techniques and measurements. Cement plates of $8 \times 8 \mathrm{~cm}$ and $6 \mathrm{~mm}$ thick, with either a smooth or rough surface, were offered as substrata for larval settlement. Rough texture was obtained from a cement cast of a mold of barnacles made by the application of silicon paste over patches of Chthamalus scabrosus Darwin and Jehlius cirratus Darwin that were abundant in the area (Jara \& Moreno 1984). Each plate was fixed to the substratum with a central screw which was inserted into a plastic rawl-plug drilled into the rocks (Fig. 2). All plates were installed at the same level of the low intertidal, with a mean distance of $3 \mathrm{~m}$ between them, ensuring that their level of wave exposure and sunlight were the same. Each plate was located near aggregations of adult Phragmatopoma virgini in randomly chosen places.

One of the species that has shown a notable decrease within the Reserve is the tube-forming polychaete Phragmatopoma virgini Kinberg, 1867. Before the initiation of the Marine Reserve, as well as during the Reserve's first years, this species formed extensive and compact tube-mass aggregations of adult worms in the low intertidal zone. Now, after $12 \mathrm{yr}$. $P$. virgini has been reduced to small aggregations, generally confined to crevices and cracks.

Because populations of this polychaete outside the Marine Reserve have not experienced such dramatic fluctuations, we postulate that the decrease observed within the Reserve is due to high post-settlement mortality produced by the increase in density of mobile consumers. This hypothesis was tested by means of a field experiment which utilized artificial plates offered as substrata for larval settlement, with which we evaluated the effect of substratum texture and the effect of exclusion of mobile consumers on the recruitment of $P$. virgini. In the scope of this work, settlement and recruitment are defined sensu Keough \& Downes (1982) and Connell (1985b).

\section{MATERIALS AND METHODS}

Study site. Observations were made at the rocky intertidal of Mehuin ( $\left.39^{\circ} 24^{\prime} \mathrm{S}, 73^{\circ} 13^{\prime} \mathrm{W}\right), 77 \mathrm{~km}$ north of the city of Valdivia (Fig. 1), in the interior of a rocky area (Punta Kilian) that the Universidad Austral de
The experimental design included 4 smooth plates, 4 rough plates, 4 smooth plates protected with cages, and 4 rough plates with cages. Cages were stainless steel with $6 \mathrm{~mm}$ mesh, a mesh size which prevented attack by benthic predators such as carnivorous snails Nucella (Acanthina) crassilabrum Martyn and Concholepas concholepas (Brugière), crabs Acanthocyclus gayi Mil. Ed, et Lucas and A. hassleri Rathbun, and the starfish Stichaster striatus (Muller \& Troschel), which are the most conspicuous macroconsumers present in this community (Moreno \& Jaramillo 1983, Sotomayor \& Zamorano 1985, Moreno et al. 1986, Godoy \& Moreno 1989, Matus 1994). Cages also acted as barriers against dislodging effects from the rasping keyhole limpets Fissurella spp.

All plates without cages were removed monthly and replaced by clean ones from June 1989 to November 1990 (18 mo). Once removed, plates were taken to the laboratory, where all organisms attached to their surface were identified and counted under a binocular microscope. The same procedure was used for plates enclosed by cages, although in this case caging was initiated in May 1990 and finished in November 1990 (7 mo).

In the case of solitary organisms, such as Phragmatopoma virgini and barnacles, counting was done with the help of a net of threads divided into 64 quadrats of $1 \mathrm{~cm}^{2}$ each. The absolute number of individuals present in each area was then recorded. For colonial organisms (e.g. bryozoans), erect and crustose 


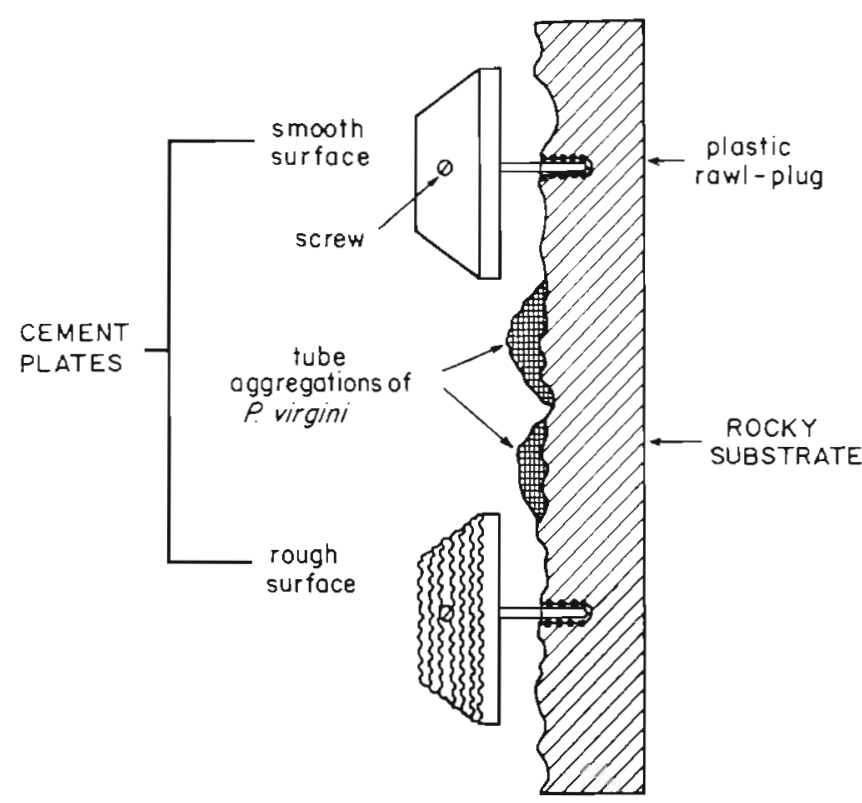

Fig. 2. Installation sketch of the smooth and rough surface cement plates. Drawing is not strictly to scale

algae and benthic diatoms, the abundance (percentage cover) was estimated by placing a net of threads with 100 uniform dots over the plates. Cover was assigned according to the number of dots that coincided with a particular species. We arbitrarily assigned $1 \%$ cover to species which were present, but not beneath a dot.

Data analysis. Data from each of the 4 experimental treatments were averaged monthly and their variance estimated. Following the recommendations of Day \& Quinn (1989), assumptions were checked prior to performing parametric statistical analyses. Bartlett's test for homogeneity of variances was used, and we observed a lack of any positive relationship between means and their variances, meaning that in spite of the small monthly sample size in each treatment $(n=4)$ we are confident that there were no violations of the assumptions of normality or homogeneity of variances. On the other hand, the complete monthly replacement of the experimental plates ensured the independence of each point in the time series

A 1-way ANOVA was used for comparing treatments in the time series, from June 1989 to November 1990, and for planned comparisons for some of the months.

The experimental exclusion of mobile consumers over smooth and rough plates was compared with a 2-way ANOVA (Treatments: exclusion or nonexclusion; Surfaces: smooth or rough), under the model: Data $=$ Constant + Treatment + Surface + Treatment $x$ Surfaces.

\section{RESULTS}

\section{Recruitment of Phragmatopoma virgini}

Recruitment of Phragmatopoma virgini occurred throughout the study, in all treatments, independent of the type of surface. A clear seasonal pattern was apparent, although it was less evident on the smooth plates. Recruitment was observed to increase towards the end of autumn (June) reaching a maximum in the middle and end of winter (August and September). In addition, a steady build up in the number of recruits was observed during the summer months (January through March) (Fig. 3).

In addition to polychaetes, the plates were colonized by bryozoans, anemones, sponges and calcareous crustose algae (Lithothamnium), but with a low cover, since as a whole they reached a maximum of $13 \%$ cover towards the beginning of spring (September). Notably, colonization of these species was highly irregular in space and time, that is, it only occurred on some plates and without a defined temporal pattern. The exception was barnacles, which recruited year round, reaching maximum abundances in autumn and spring with a mean density between 112 (SD \pm 24 ) and 165 $(\mathrm{SD} \pm 38)$ ind. $64 \mathrm{~cm}^{-2}$, respectively. Plates were also colonized seasonally by algae, notably Iridaea ciliata Kutzing and Rhizoclonium sp. Cover of both species showed a maximum in spring (October to November) with an average cover of $25.3 \%(\mathrm{SD} \pm 4.7)$ and $18.7 \%$ $(\mathrm{SD} \pm 6.1)$, respectively.

\section{Effects of surface texture}

To assess the effect that plate surface texture had on recruitment, we examined a period of low recruitment intensity (December 1989) and a period of high intensity (August 1990). A 1 -way ANOVA revealed that in both periods there were significant differences in the magnitude of recruitment between smooth and rough surfaces (low period $F=15.12$, p $<0.01$; high period $F$ $=47.6, p<0.001)$. Recruitment was always higher on rough plates. In fact, during the low recruitment period the mean number of recruits on smooth plates was approximately one-fifth of that registered on rough surfaces, while during the period of high recruitment intensity the relative proportion reached almost oneninth.

\section{Effect of exclusion experiment}

Exclusion cages acted as an effective barrier to macroconsumers, as we never detected their presence 


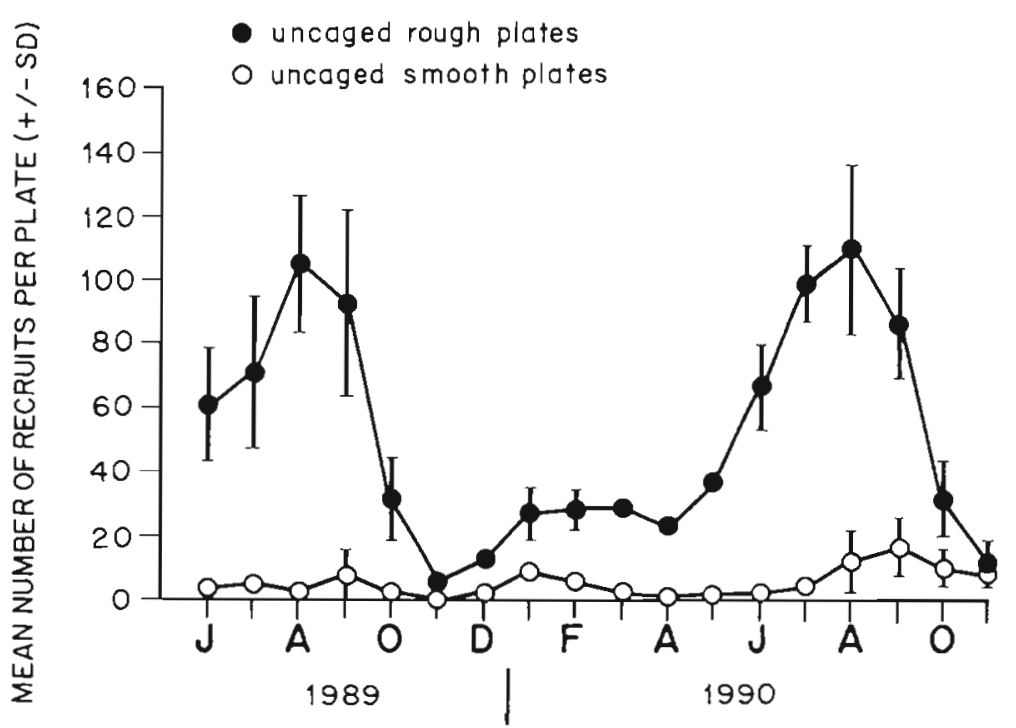

Fig. 3. Phragmatopoma virgini. Monthly estimates (mean $\pm \mathrm{SD}$ ) of the number of recruits on uncaged rough and smooth plates from June 1989 to November 1990

within cages. However, during spring and summer we did detect, inside the exclusion cages, the presence of juvenile crabs of 2 species, Acanthocyclus spp. and Petrolisthes spp. These crabs were very small, with a maximum carapace length of 3 to $5 \mathrm{~mm}$. They were utilizing the narrow cavity between the plates and the substratum as a refuge. Although their effect on the organisms settled on plates is unknown, there were also crabs sheltering beneath the uncaged plates, so any effect should be the same in both treatments.

When smooth and rough plates enclosed by cages were compared between May and November (Fig. 4), we did not detect any significant differences in the mean number of recruits present on both types of surfaces. In both cases, the mean number of recruits fol-

Table 1 Results of 2-factor ANOVA for the exclusion of mobile consumers (Exc) over plates of smooth and rough surfaces (Surf). Analyses were done for a period of (A) low recruitment (May 1990) and one of (B) high recruitment (August 1990) of Phragmatopoma virgin. For treatments and controls

$$
\mathrm{n}=4 \text { plates }
$$

\begin{tabular}{|lccccc|}
\hline Source & Sum of squares & DF & Mean square & F-ratio & $p$ \\
\hline (A) May 1990 & & & & & \\
Exc & 1701.56 & 1 & 1701.56 & 29.08 & 0.001 \\
Surf & 4128.06 & 1 & 4128.06 & 70.54 & 0.001 \\
Exc $\times$ Surf & 33.06 & 1 & 33.06 & 0.56 & 0.467 \\
Error & 702.25 & 12 & 58.52 & & \\
(B) August 1990 & & & & & \\
Exc & 4830.25 & 1 & 4830.25 & 7.68 & 0.01 \\
Surf & 22801.0 & 1 & 2801.0 & 36.26 & 0.001 \\
Exc $\times$ Surf & 1849.0 & 1 & 1849.0 & 2.941 & 0.112 \\
Error & 7545.5 & 12 & 628.8 & & \\
\hline
\end{tabular}

lowed a similar pattern of abundance throughout time, with an increase between July and September, although it was lesser on the smooth plates. When the monthly mean number of recruits on smooth and rough caged plates was compared with the uncaged plates, we detected highly significant differences only for the smooth plates $(p<0.001)$, except in November. There were no significant differences for uncaged rough plates. This means that uncaged rough plates, in spite of the fact that they supported a lesser mean number of recruits, responded similarly to the smooth and rough caged plates.

The results of the 2-way ANOVA comparing the simultaneous effect of mobile consumers and that of surface texture revealed that, during the period of low intensity recruitment, the effect of exclusion and that of surface texture were both highly significant (Table 1). Contrary to our expectations, there was no interaction between the type of surface and the effect of mobile consumers

A very similar pattern was apparent during the high intensity recruitment period (Table 1), although there was a tendency for predation to be less important, probably due to a greater availability of food on the plates.

\section{DISCUSSION}

One of the most important factors affecting the settlement of benthic organisms is the behaviour of larvae at the time of settlement, mostly with respect to habitat selection (e.g. Davis 1987). Larvae respond to several, often complex, environmental stimuli (reviewed by Pawlik 1992).

It has been clearly demonstrated that several factors affect the settlement behaviour of species within the polychaete family Sabellariidae. Cues of a biochemical nature appear to have the most powerful influence on larval settlement and metamorphosis within this family (reviewed by Eckelbarger 1978). The chemical cue is a cement secreted by the worm when forming the matrix of the adult sand tubes and the mucoid tube of juveniles (Wilson 1968, Pawlik 1986).

Although we lack this information for Phragmatopoma virgini, we can assume that it has a behaviour similar to those 


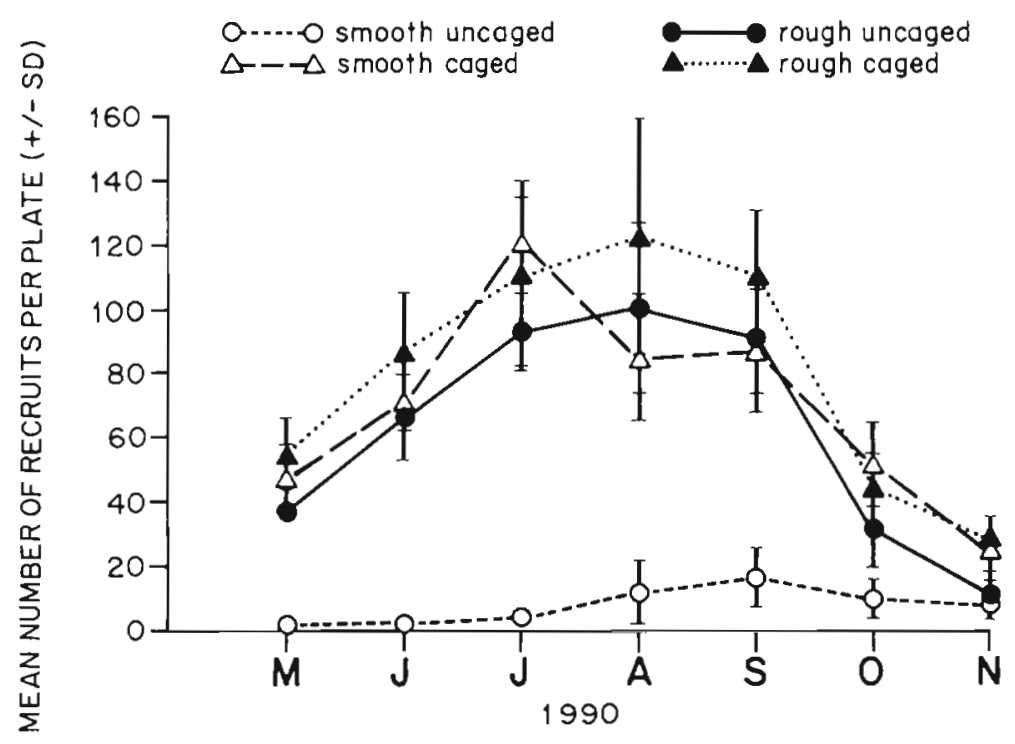

Fig. 4. Phragmatopoma virgini. Monthly estimates (mean \pm SD) of the number of recruits on smooth and rough caged plates (exclusion) compared with smooth and rough uncaged plates from May to November 1990 fornica are capable of dominating the substratum, both holding space and overgrowing other species, in the absence of frequent disturbance or intense postmetamorphic mortality. A situation analogous to this could explain the observed contrast in the levels of abundance in $P$. virgini at the low intertidal of the Marine Reserve and adjacent areas. Outside the Reserve, perturbation due to the activity of herbivorous and carnivorous snails is strongly reduced, since they are permanently harvested by local fishermen for consumption (Moreno et al. 1984, Godoy \& Moreno 1989). Therefore, in the presence of a low disturbance frequency, the worm aggregations can dominate space and persist in that intertidal area. On the other hand, at the Marine Reserve the higher perturbation frequency introduces a high post-settlement mortality that reduces the probability of successful recruitment.

other species in the family which show gregarious settlement. If this inference is correct, then settlement and recruitment of $P$. virgini should occur preferentially on aggregations of adult tubes that, as already noted, are reduced to only crevices and cracks in the low intertidal of the Marine Reserve. We also observed $P$. virgini larvae recruits on plates that were in close contact with the adult tubes. This may constitute the way in which this species colonizes new substrata and thereby expands its lateral distribution. Wilson (1971) observed a similar phenomenon in Sabellaria alveolata (L.) on the English coast and noted fusion with other aggregations.

The recruitment of Phragmatopoma virgini during all months of the year and the marked seasonality constitute an indicator of larval abundance in the plankton. Since the seasonal pattern appeared on all the plates, including those enclosed by cages, we can disregard the possibility that this pattern was produced by mobile consumers. In spite of the continuous occurrence of recruitment, aggregations of adult worms already present on the natural substratum did not experience space expansion, even during periods of peak recruitment. This observation is also supported by the greater density of recruits on the plates from which consumers were excluded, clearly demonstrating that the decrease in population abundance on the natural substratum is not produced by an absence of recruits, but post-settlement mortality induced by mobile consumers.

Taylor \& Littler (1982) and Jensen \& Morse (1984) have shown that aggregations of Phragmatopoma cali-
The surface texture of the artificial uncaged plates had a dramatic effect on recruitment, as is seen in the extreme differences in the mean number of recruits observed on smooth and rough plates. These differences probably result from the fact that the rough surface provides a refuge from consumers for the newly settled polychaetes. Nevertheless, the fact that no interaction was detected between surface texture and the exclusion of consumers suggests that the refugial effect may be more important in the avoidance of dislodgement rather than predation. This may be explained by the fact that dislodgement is more easily achieved on smooth surfaces, while predators can consume individuals settled on both types of surface.

Unfortunately, experimental design restrictions did not permit us to distinguish which factors could be operating simultaneously with respect to effects on recruitment intensity. One of the possible factors could be the preference of the larvae of Phragmatopoma virgini for a particular surface texture when settling, as demonstrated by Wilson (1968) for Sabellaria alveolata, which showed a slight preference for settling on rough surfaces. But, in our experiment, the high recruitment observed on caged smooth plates being similar to that which occurred on both caged and uncaged rough plates allowed us to disregard, to some extent, larvae settling preference with respect to type of surface.

Other possible influences can come from microenvironmental conditions generated over the rough surfaces (e.g. greatest water retention, microcurrents, boundary layer effects). Also, the effects that cages 
have on the hydrodynamics of their boundaries, which could affect larval settlement on both sorts of plates, must be taken into account. These kinds of factors, all of which can contribute to enhance settlement and greater post-settlement survival, should be assessed in the future in order to determine their real magnitude.

These influences and their effects on settlement and mortality occur on a small temporal and spatial scale. The benthic community at the Marine Reserve of Mehuin has been protected from human perturbation for almost 12 yr (see Moreno et al. 1984) and has experienced changes as a result, mostly increases in densities of molluscs, herbivores and carnivores which were previously collected by local gatherers.

Nevertheless, as the recruitment of Phragmatopoma virgini and some of its predators, all having pelagic larvae, undergoes unpredictable changes from one year to the next, it could be expected that the relative importance of the studied relationships alters over time. In other words, in periods of high settlement of $P$. virgini the effects of predation and/or dislodging would be scarce, while it would be greater in periods of low settlement. Consequently, different generations of the polychaete could be submitted to different postsettlement survival conditions, demonstrating the effects that environmental variations have on community structure.

Acknowledgements. This research was partially supported by the Fondo Nacional de Ciencia y Tecnología (FONDECYTChile) Grant No. 062-89. We are grateful to Drs Fernando Jara and Andrew Davis for their constructive comments on the manuscript. We are also indebted to $G$. Asencio and R. Reyes for their field assistance.

\section{LITERATURE CITED}

Barry JP (1989) Reproductive response of a marine annelid to winter storms: an analog to fire adaptation in plants? Mar Ecol Prog Ser 54:99-107

Caffey $\mathrm{H}$ (1985) Spatial and temporal variation in settlement and recruitment of intertidal barnacles. Ecol Monogr 55: $313-332$

Connell JH (1961) Effects of competition, predation by Thais lapillus, and other factors on natural populations of the barnacle Balanus balanoides. Ecol Monogr 31:61-104

Connell JH (1985a) Variation and persistence of rocky shore populations. In: Moore PG, Seed R (eds) The ecology of rocky coasts. Hodder and Stoughton, London, p 57-69

Connell JH (1985b) The consequences of variation in initial settlement vs post-settlement mortality in rocky intertidal communities. J exp mar Biol Ecol 93:11-45

Davis AR (1987) Variation in recruitment of the subtidal colonial ascidian Podoclavella cylindrica (Quoy \& Gaimard): the role of substratum choice and early survival. J exp mar Biol Ecol 106:57-71

Davis AR (1988) Colony regeneration following damage and size-dependency mortality in the Australian ascidian Podoclavella moluccensis. J exp mar Biol Ecol 123: $269-285$
Day RW, Quinn GP (1989) Comparisons of treatments after an analysis of variance in ecology. Ecol Monogr 59:433-463

Denley EJ, Underwood AJ (1979) Experiments on factors influencing settlement, survival, and growth of two species of barnacles in New South Wales. J exp mar Biol Ecol 36:269-293

Eckelbarger KJ (1978) Metamorphosis and settlement in the Sabellariidae. In: Chia FS, Rice $M$ (eds) Settlement and metamorphosis of marine invertebrate larvae. Elsevier, New York, p 145-164

Gaines S, Roughgarden J (1985) Larval settlement rate: a leading determinant of structure in an ecological community of the marine intertidal zone. Proc natl Acad Sci USA 82:3707-3711

Godoy C, Moreno CA (1989) Indirect effects of human exclusion from the rocky intertidal in southern Chile: a case of cross-linkage between herbivores. Oikos 54:101-106

Gotelli NJ (1987) Spatial and temporal patterns of reproduction, larval settlement and recruitment of the compound ascidian Aplidium stellatum. Mar Biol 94:45-51

Hawkins SJ, Hartnoll RG (1982) Settlement patterns of Semibalanus balanoides (L.) in the Isle of Man (1977-1981). $\mathrm{J}$ exp mar Biol Ecol 62:271-283

Jara HF (1980) Herbivoria y dominancia competitiva de Iridaea boryana (Setch et Gardn) Skottsb, en un frente rocoso semiprotegido del Sur de Chile. Tesis, Instituto de Ecología y Evolución, Facultad de Ciencias, Universidad Austral de Chile, Valdivia

Jara HF, Moreno CA (1984) Herbivory and structure in a midlittoral rocky community: a case in southern Chile. Ecology 65:26-38

Jensen RA, Morse DE (1984) Instraspecific facilitation of larval recruitment: gregarious settlement of the polychaete Phragmatopoma californica (Fewkes). J exp mar Biol Ecol 83:107-126

Keough MJ (1983) Patterns of recruitment of sessile invertebrates in two subtidal habitats. J exp mar Biol Ecol 66 : $213-245$

Keough MJ, Downes BJ (1982) Recruitment of marine invertebrates: the role of active larval choices and early mortality. Oecologia 54:348-352

Matus LI (1994) Ecología trófica de Stichaster striatus Muller y Troschel 1840 (Echinodermata: Asteroidea) en la Reserva Marina de Mehuin. Valdivia, Chile. Tesis Magister en Ciencias, Universidad Austral de Chile, Valdivia

Moreno CA, Jaramillo E (1983) The role of grazers in the zonation of intertidal macroalgae of the Chilean coast. Oikos 41:73-76

Moreno CA, Lunecke KM, Lépez MI (1986) The response of an intertidal Concholepas concholepas (Gastropoda) population to protection from man in southern Chile and the effects on benthic sessile assemblages. Oikos 46:359-364

Moreno CA, Sutherland JP, Jara HF (1984) Man as a predator in the intertidal zone of southern Chile. Oikos 42:155-169

Pawlik JR (1986) Chemical induction of larval settlement and metamorphosis in the reef-building tube worm Phragmatopoma californica (Sabellariidae: Polychaeta). Mar Biol 91:59-68

Pawlik JR (1992) Chemical ecology of the settlement of benthic marine invertebrates. Oceanogr mar biol A Rev 30: $273-335$

Sotomayor JF, Zamorano JH (1985) Hábitos alimentarios de Acanthocyclus gayd Milne Edwards y Lucas 1844 y A hassleri Rathbun 1898 (Decapoda-Atelecyclidae), en el intermareal rocoso de Mehuín, Chile. Medio Ambiente, Chile 7(2):135-142

Stoner DS (1990) Recruitment of a tropical colonial ascidian: 
relative importance of pre-settlement vs post-settlement processes. Ecology 71:1682-1690

Taylor PR, Littler MM (1982) The roles of compensatory mortalıty, physical disturbance, and substrate retention in the development and organization of a sand-influenced, rocky intertidal community. Ecology 63:135-146

Wilson DP (1968) The settlement behaviour of the larvae of Sabellaria alveolata (L.). J mar biol Ass UK 48:387-435

This article was submitted to the editor
Wilson DP (1971) Sabellaria colonies at Duckpool. North Cornwall, 1961-1970. J mar biol Ass UK 51:509-580

Young CM, Chia FS (1984) Microhabitat associated variability in survival and growth of subtidal solitary ascidians during the first 21 days after settlement. Mar Biol 81:61-68

Yund PO, Cunningham CW, Buss LW (1987) Recruitment and postrecruitment interactions in a colonial Hydroid. Ecology 68:971-982

Manuscript first received: July 11, 1994

Revised version accepted: May 9, 1995 